\title{
Surgical repair of orbital fat prolapse by conjunctival fixation to the sclera
}

\author{
This article was published in the following Dove Press journal: \\ Clinical Ophthalmology \\ 18 September 2015 \\ Number of times this article has been viewed
}

\author{
Natsuko Nakamura' \\ Kunihiko Akiyama ${ }^{1,2}$ \\ Chika Shigeyasu',3 \\ Masakazu Yamada ${ }^{1,3}$ \\ 'Division for Vision Research, \\ National Institute of Sensory Organs, \\ National Tokyo Medical Center, Tokyo, \\ ${ }^{2}$ Department of Ophthalmology, \\ National Tokyo Medical Center, Tokyo, \\ ${ }^{3}$ Department of Ophthalmology, \\ Kyorin University School of Medicine, \\ Mitaka, Japan
}

Purpose: The aim of the study described here was to report the outcomes of surgery for orbital fat prolapse by conjunctival fixation to the sclera.

Patients and methods: Twenty-three consecutive eyes of 19 patients with orbital fat prolapse were retrospectively reviewed. All cases were treated with the same simple procedure without resection through conjunctival incision: fixation of conjunctiva to the sclera with interrupted sutures of 10-0 nylon in two rows located approximately $12-14 \mathrm{~mm}$ posterior to the limbus. These sutures formed an embankment to keep the prolapsed fat posteriorly. Postoperative results were determined by slit-lamp examination and recurrence of prolapse was defined as the presence of orbital fat anterior to the embankment.

Results: During the mean follow-up period of 19 months (range: 1-59 months), one case experienced recurrence which required further surgery. None of the other cases experienced recurrence, and there were no intraoperative or postoperative complications.

Conclusion: Conjunctival fixation to the sclera was a simple and effective surgical technique for orbital fat prolapse, with less invasion compared to the conventional method that requires conjunctival incision.

Keywords: surgical technique, herniation, orbital fat, conjunctiva, suture, 10-0 nylon

\section{Introduction}

Orbital fat prolapse is a movable yellowish mass beneath the conjunctiva, ${ }^{1,2}$ typically located in the superotemporal quadrant. ${ }^{3}$ It is associated with localized weakness or thinning of Tenon's capsule usually caused by aging or surgical trauma., ${ }^{1,2}$ Males have been reported to be affected more likely than females. ${ }^{1,3,4}$ Surgery is considered for irritative symptoms or for cosmetic reasons. A standard surgical method is the resection of herniated fat through conjunctival incision with or without connective tissue repair. ${ }^{1-9}$ Alternative methods without resection have been reported, including suture-less repair using fibrin glue ${ }^{7}$ and conjunctival fixation to the sclera. ${ }^{10}$ Among these methods, conjunctival fixation to the sclera, described by Otaka and $\mathrm{Kyu},{ }^{10}$ is a more simple and less invasive technique than the standard method. However, to our knowledge, there have been no reports describing the postoperative results in a large number of patients to date. In the study reported here, we retrospectively reviewed the outcome of this procedure, which involved some modifications to the original technique.

\section{Patients and methods}

Twenty-three consecutive eyes of 19 patients who were treated surgically for orbital fat prolapse at the National Hospital Organization Tokyo Medical Center, Tokyo, Japan, from August 2006 to January 2013 were retrospectively reviewed in this study. The study protocols followed the tenets of the Declaration of Helsinki and were approved by the local Ethics Committee of the Tokyo Medical Center.
Correspondence: Masakazu Yamada Department of Ophthalmology, Kyorin University School of Medicine, 6-20-2 Shinkawa, Mitaka, Tokyo I8I-86II, Japan Tel +8 I 4224755 I I

Fax +8I 422440674

Email yamada@eye-center.org 
At the first visit, comprehensive ophthalmic examinations were performed in all patients including measurement of visual acuity, intraocular pressure, slit-lamp biomicroscopy with fluorescein staining and indirect ophthalmoscopy. The diagnosis was made by slit-lamp examination of a typical yellowish, elevated mass beneath the conjunctiva. Other orbital disorders such as dermolipoma, epibulbar dermoid, and lymphoid tumor were differentiated clinically by their appearance and mobility, which is a distinctive characteristic of orbital fat prolapse. ${ }^{1,2}$ The mobility was confirmed by repositioning the mass into the orbit with slight pressure (Figure 1A, B). Lacrimal gland prolapse was also differentiated by observing the normal appearance of the palpebral lobe of the gland under the upper eyelid.

The exclusion criteria were recurrent cases after orbital fat surgery, history of any orbital disorders, and suspicious symptoms of other orbital diseases such as impaired ocular movement or exophthalmos. All cases were treated with the same surgical technique, involving conjunctival fixation to the sclera (Figure 1C, D). Efficacy and safety during the follow-up period were determined as the outcomes.

After obtaining written informed consent for the surgical procedure, the surgery was performed under local anesthesia with subconjunctival injection of $2 \%$ lidocaine. After rotating the eye to the opposite direction of the lesion using a traction suture, the prolapsed fat was slid posteriorly and repositioned into the orbit with gentle compression using a blunt instrument like a spatula. While the fat was kept repositioned by an assistant, conjunctiva in the quadrant of the fat prolapse was fixated to the sclera with 8-10 interrupted sutures of 10-0 nylon, in two rows located approximately $12-14 \mathrm{~mm}$ posterior to the limbus measured with a caliper (Figure 2). As the depth of the sutures was not recognized easily beneath the conjunctiva and Tenon's capsule, the sutures were placed through the superficial layer of the sclera to prevent perforation. The distance between the two rows of sutures was not fixed precisely but was approximately $1-2 \mathrm{~mm}$. The knots were buried in the sclera to avoid irritation after the surgery. These sutures were expected to form an embankment to keep the prolapsed fat at the posterior position, and were not to be removed after the treatment unless they caused any complaint such as irritation or pain. Antibiotic and steroid eye drops were prescribed for 1 month postoperatively to prevent infection and to lessen inflammation.
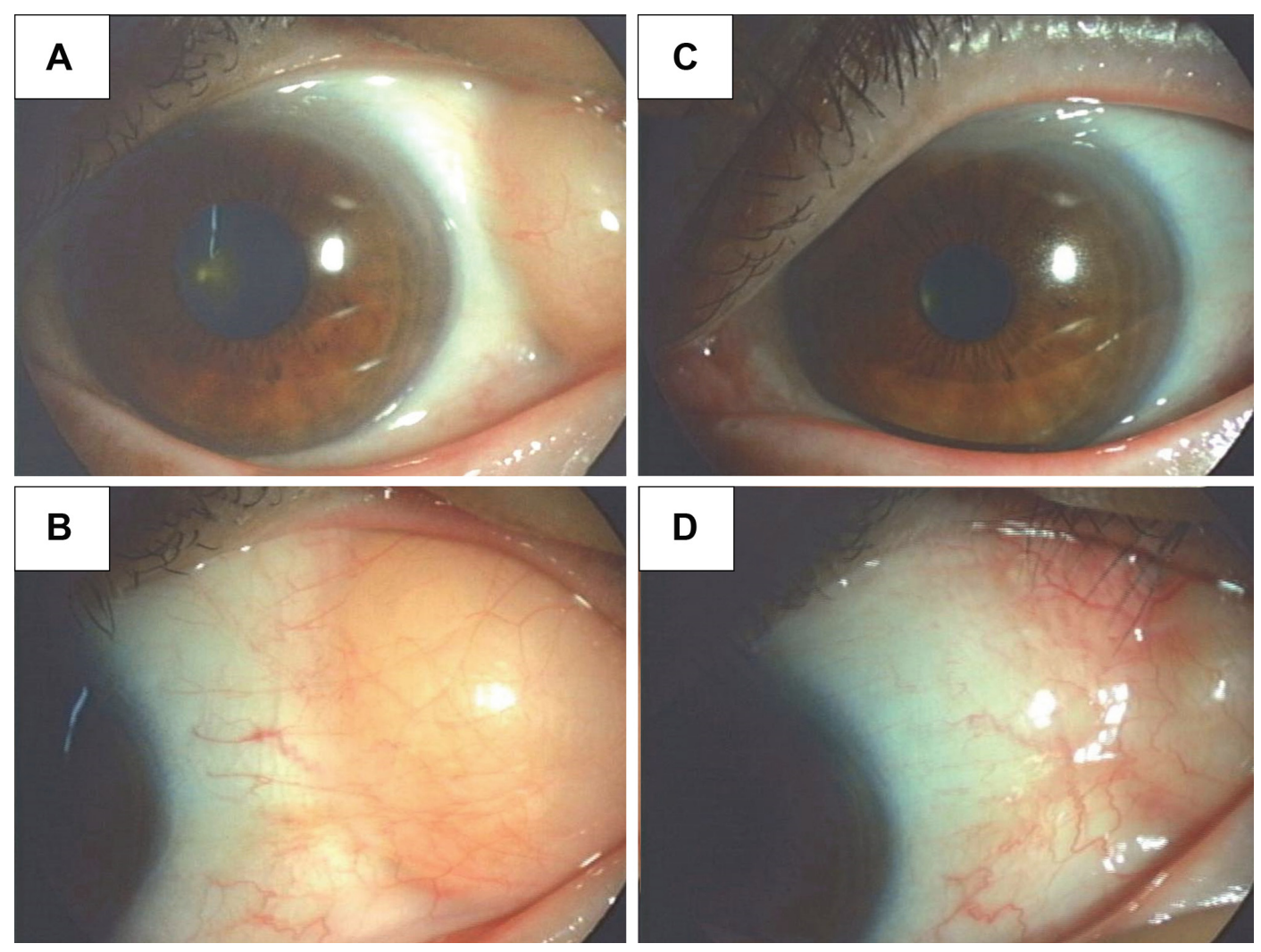

Figure I Preoperative and postoperative appearance of orbital fat prolapse.

Notes: (A, B) A prominent orbital fat prolapse is present beneath the conjunctiva in the superotemporal quadrant. (C, D) After conjunctival fixation to the sclera, orbital fat is well fixed to the posterior. 


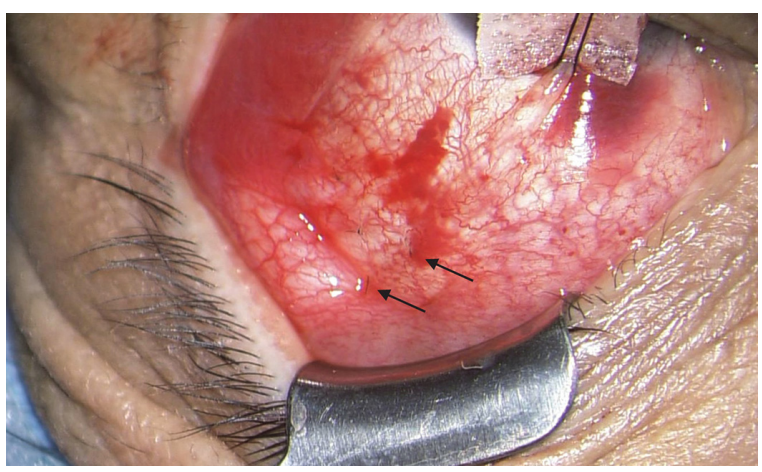

Figure 2 Surgical procedure of conjunctival fixation to the sclera. Conjunctiva was fixated to the sclera with 8-10 interrupted sutures of $10-0$ nylon in two rows (arrows) located approximately $12-14 \mathrm{~mm}$ posterior to the limbus.

The patients were observed at 1 day, 1 week, and 1 month after surgery, and subsequently were examined every 2-6 months according to the condition of each patient. At each visit after the operation, the efficacy of the surgery was determined by slit-lamp examination. The condition of the ocular surface was also determined using fluorescein staining. Recurrence was defined as the presence of orbital fat anterior to the embankment.

\section{Results}

The age of the patients at operations was $64.9 \pm 10.4$ years (average age \pm standard deviation; range: $45-82$ years). All the patients were male except for one female who had a unilateral lesion. Among the 23 eyes, eight eyes (four patients) were bilateral cases and 15 eyes were unilateral cases. All cases had orbital fat prolapse in the superotemporal quadrant. None of them had any other ocular or orbital disorder that would exclude them from the study. The mean follow-up period was 19 months (range: $1-59$ months).

There were no intraoperative or postoperative complications, such as disorders of eye movements, decreased visual acuity, increased or decreased intraocular pressure, ocular recession, retinal detachment, or severe bleeding. No conjunctival folds or fibrosis were observed at the sutured site during the follow-up period. Slit-lamp examination with fluorescein staining revealed no severe disturbance of the tear film either preoperatively or postoperatively.

A 67-year-old male experienced recurrence at 36 months after the surgery. There was a large fat prolapse before the initial operation, which had been located adjacent to the limbus, and the recurrent prolapse presented with a similar appearance. Reoperation was performed at 42 months with the standard surgical method of fat resection through conjunctival incision. No further recurrence was seen.

\section{Discussion}

Surgical repair of orbital fat prolapse is indicated for discomfort or for cosmetic complaints. Although a standard surgical method involves resection of herniated fat through conjunctival incision, a less invasive method is desirable for this disorder. Among several reports in the literature, conjunctival fixation to the sclera, introduced by Otaka and $\mathrm{Kyu},{ }^{10}$ appears to be the least invasive, consisting of very simple procedures and requiring no conjunctival incision.

Some modifications were made to the original method. We used 10-0 nylon sutures, $12-14 \mathrm{~mm}$ posterior to the limbus, whereas 6-0 Vicryl ${ }^{\mathrm{TM}}$ sutures were located 8-10 mm posterior to the limbus in the original report. ${ }^{10}$

We selected 10-0 nylon for its thin, monofilament and nonabsorbable features instead of 6-0 Vicryl ${ }^{\mathrm{TM}}$, to reduce postsurgical irritation and inflammation. However, postsurgical inflammation was used to facilitate adhesion between the conjunctiva and the sclera, and was an essential element of this method. ${ }^{10}$ The lower inflammation and adhesion resulting from the 10-0 nylon sutures would have been a disadvantage. Additionally, the thin suture threads of 10-0 nylon may not have had enough strength to form an embankment, long after the surgery. In order to overcome these disadvantages, as many as $8-10$ sutures were located in two rows. This procedure could be performed simply, and no complications were observed.

The suture threads were placed more posteriorly than described in the original article ${ }^{10}$ to create the embankment as far as possible from the limbus to result in a better cosmetic outcome. Consequently, the stitches were safely located 12-14 $\mathrm{mm}$ from the limbus in all cases.

Recurrence was seen in one case. At the initial examination, this case had a large volume of fat prolapse which nearly reached the limbus. In cases with prominent prolapse, the pressure of the mass toward the embankment would easily overcome the adhesive strength of the sutures after the surgery. Additional suture threads or stronger suture material such as Vicryl might prevent recurrence in such cases, and could serve as a desirable supplementary procedure for re-treatment of recurrent cases using the same surgical method.

The embankment in this procedure was primarily formed by the mechanical attachment of the conjunctiva, Tenon's capsule, and the sclera. Because 10-0 nylon monofilament suture loses its strength in several years, the long-lasting efficacy of the operation might have been provided by the adhesive scarring created by the apposition of conjunctiva and Tenon's layer, as Sniegowski et al suggested in a report 
of cases repaired with fibrin glue. ${ }^{7}$ They also reported that sufficient adhesion strength would be achieved within 1 week through apposition of the tissues.

Additionally, if the sutures were located around the break of Tenon's capsule or intermuscular septa from which the prolapsed fat protrudes, ${ }^{6}$ the scar formation would reconstruct the break successfully. The long-term efficacy might have depended on whether the sutures maintained their strength until the adhesive scar was formed. Recent progress in ocular imaging has enabled the detailed evaluation of the anterior segment and the ocular surface such as filtering blebs with the aid of optical coherence tomography. ${ }^{11}$ This technique may provide useful knowledge about the adhesive scarring process after this surgical procedure.

In the present study, the efficacy of conjunctival fixation to the sclera proved to be effective to treat orbital fat prolapse. Because the time limit for the sutures or adhesive scar to maintain the embankment was unknown, continuous observation was necessary to ensure its longterm efficacy.

\section{Conclusion}

Surgery for orbital fat prolapse by conjunctival fixation to the sclera may be a more simple and less invasive procedure than surgery using conjunctival incision and fat resection.

\section{Author contributions}

NN: design, writing and revision of the manuscript, data collection; KA: design, writing and revision of the manuscript, data collection and interpretation; CS: concept, design, revision of the manuscript; MY: concept, design, data collection and interpretation, revision of the manuscript.
All authors contributed toward data analysis, drafting and revising the paper and agree to be accountable for all aspects of the work.

\section{Disclosure}

The authors report no conflicts of interest in this work. This research received no specific grant from any funding agency.

\section{References}

1. Glover AT, Grove AS Jr. Subconjunctival orbital fat prolapse. Ophthal Plast Reconstr Surg. 1987;3(2):83-86.

2. Jordan DR, Tse DT. Herniated orbital fat. Can J Ophthalmol. 1987; 22(3):173-177.

3. McNab AA. Subconjunctival fat prolapse. Aust NZJ Ophthalmol. 1999; 27(1):33-36.

4. Siban M, Weijtens O, van den Bosch W, Paridaens D. Efficacy of transconjunctival excision of orbital fat prolapse: a long-term follow-up study. Acta Ophthalmol. 2014;92(3):291-293.

5. Monner J, Benito JR, Zayuelas J, Paloma V, Castro V, Serra JM. Transconjunctival herniation of orbital fat. Ann Plast Surg. 1998;41(6): 658-661.

6. Sato K, Yamaguchi T, Yokota H. A surgical technique with connective tissue repair for the management of subconjunctival orbital fat prolapse. Clin Experiment Ophthalmol. 2006;34(9):841-845.

7. Sniegowski MC, Kelmenson A, Gregory DG, Durairaj VD. Smallincision, sutureless repair of subconjunctival fat prolapse. Ophthal Plast Reconstr Surg. 2012;28(3):221-223.

8. Viana GA, Osaki MH, Filho VT, Sant'Anna AE. Prolapsed orbital fat: 15 consecutive cases. Scand J Plast Reconstr Surg Hand Surg. 2009; 43(6):330-334.

9. Stangos AN, Hamedani M. Spontaneous subconjunctival orbital fat prolapse: presentation of four cases. Klin Monbl Augenheilkd. 2006;223(5):415-417.

10. Otaka I, Kyu N. A new surgical technique for the management of orbital fat prolapse. Am J Ophthalmol. 2001;131(2):267-269.

11. Napoli PE, Zucca I, Fossarello M. Qualitative and quantitative analysis of filtering blebs with optical coherence tomography. Can J Ophthalmol. 2014;49(2):210-216.
Clinical Ophthalmology

\section{Publish your work in this journal}

Clinical Ophthalmology is an international, peer-reviewed journal covering all subspecialties within ophthalmology. Key topics include: Optometry; Visual science; Pharmacology and drug therapy in eye diseases; Basic Sciences; Primary and Secondary eye care; Patient Safety and Quality of Care Improvements. This journal is indexed on Submit your manuscript here: http://www.dovepress.com/clinical-ophthalmology-journal

\section{Dovepress}

PubMed Central and CAS, and is the official journal of The Society of Clinical Ophthalmology (SCO). The manuscript management system is completely online and includes a very quick and fair peer-review system, which is all easy to use. Visit http://www.dovepress.com/ testimonials.php to read real quotes from published authors. 